\title{
Study of Nail Psoriasis and Dermoscopic Correlation with Dermoscopic and Modified Dermoscopic Nail Psoriasis Severity Indexes (dNAPSI and dmNAPSI)
}

\author{
Sandeep Arora ${ }^{1}$, Debatraya Paul ${ }^{2}$, Richa Kumar $^{3}$, Anuj Bhatnagar ${ }^{2}$, Gulhima Arora $^{4}$, \\ Sunita Mech², Devinder Kumar Suhag ${ }^{2}$
}

\author{
1 Department of Dermatology, Army College of Medical Sciences \& Base Hospital Delhi Cantt, India \\ 2 Command Hospital Air Force Bangalore, India \\ 3 Command Hospital Eastern Command Kolkota, India \\ 4 Mehektagul Dermaclinic, New Delhi, India
}

Key words: Nail psoriasis, nail psoriasis severity index, psoriasis area severity index, dermoscopy, onychoscopy

Citation: Arora S, Debatraya P, Richa K et al. Study of nail psoriasis and dermoscopic correlation with dermoscopic and modified dermoscopic nail psoriasis severity indexes (dNAPSI and dmNAPSI). Dermatol Pract Concept. 2022;12(1):e2022010. DOI: https://doi .org/10.5826/dpc.1201a10

Accepted: May 4, 2021; Published: January 2022

Copyright: (02022 Arora et al. This is an open-access article distributed under the terms of the Creative Commons

Attribution-NonCommercial License (BY-NC-4.0), https://creativecommons.org/licenses/by-nc/4.0/, which permits unrestricted noncommercial use, distribution, and reproduction in any medium, provided the original authors and source are credited.

Funding: None.

Competing interests: None.

Authorship: All authors have contributed significantly to this publication.

Corresponding author: Sandeep Arora, Army College of Medical Sciences \& Base Hospital Delhi Cantt, India. E-mail: aroraderma@gmail.com

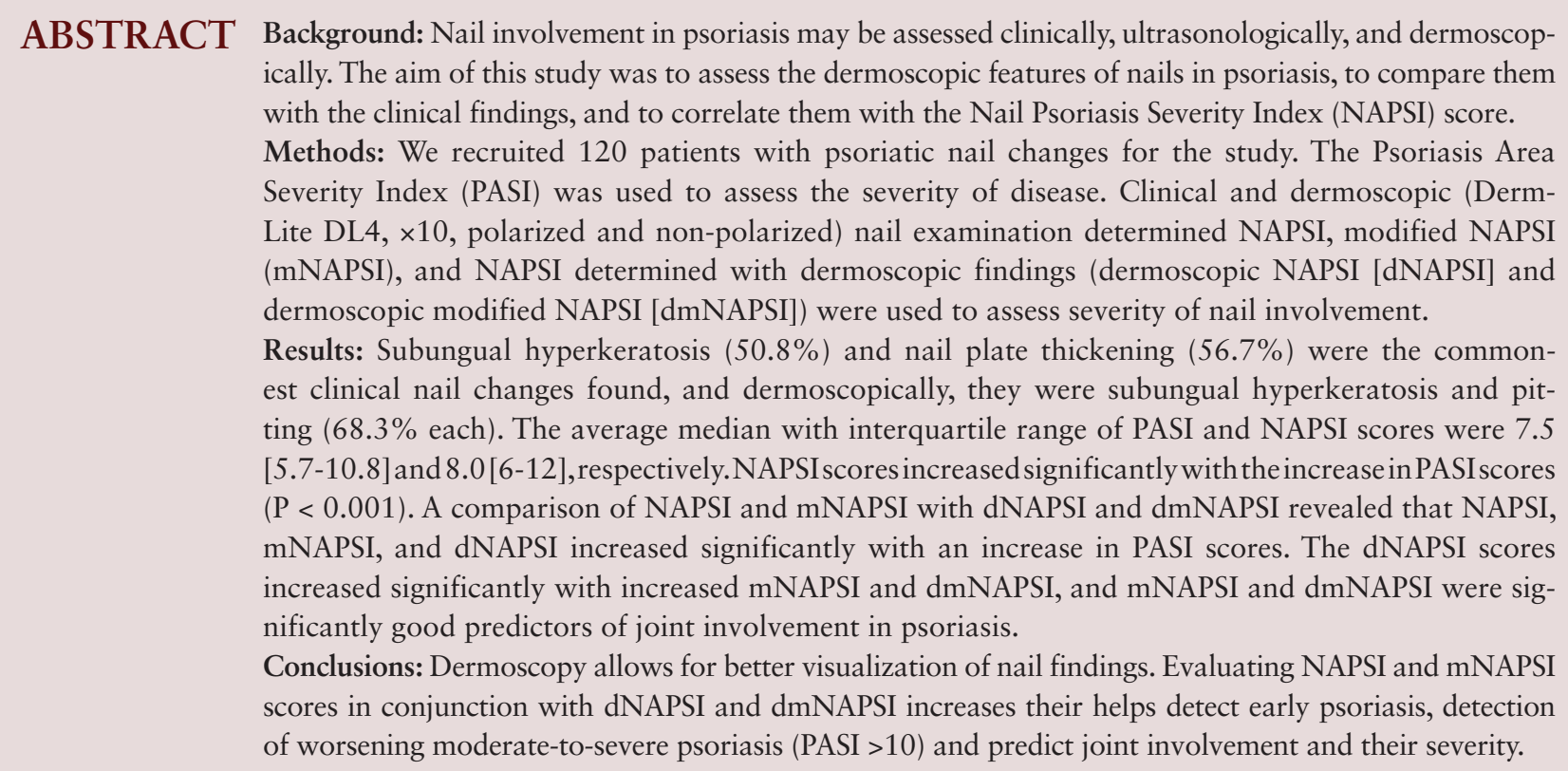




\section{Introduction}

Nail changes in psoriasis are significant findings and associated with a significant psychological impact [1]. Nail lesions are observed in about one-half of patients with psoriasis, with an estimated lifetime incidence of $80-90 \%$ [2]. Most psoriasis cases present with nail changes, while isolated nail psoriasis is rare, occurring in $1-5 \%$ of patients [3]. These changes are most common in older patients, in severe forms of psoriasis, in cases with longer duration of disease, and in the presence of psoriatic arthritis, in which case the incidence of nails changes is over $80 \%$ [4]. More severe nail psoriasis is associated with a more severe cases of psoriatic arthritis [5].

The clinical presentation of nail psoriasis varies according to the severity and localization of the lesion: the nail matrix, the nail bed, and in severe forms, the entire nail structure $[6,7]$. The most common nail lesion reported is pitting, followed by nail bed discoloration, onycholysis, subungual hyperkeratosis, abnormalities of the nail plate, and splinter hemorrhages [8]. They lead to significant functional impairment, pain, and psychosocial distress, and patients report significantly worse values in satisfaction with their treatment due to the stress and time involved in treatment [2,9].

Dermoscopy with polarized and non-polarized modes is useful in the evaluation of superficial nail plate/matrix changes, such as pitting and crumbling, and deeper nail bed psoriatic nail involvement in the form of onycholysis, oil spots, subungual hyperkeratosis and splinter hemorrhages, especially when there are no typical clinical features $[10,11]$.

\section{Objectives}

The focus of our study was to determine the frequency of dermoscopic findings in psoriatic nails and to compare the dermoscopic examination with the clinical examination to investigate the relationships between the indicators of disease severity.

\section{Methods}

This was a prospective observational study conducted from October 2018 to October 2019 in the Department of Dermatology in a tertiary care teaching hospital. Approval from the institutional ethics committee of Command Hospital Air Force Bangalore was obtained vide EC/CHAF Bangalore/2018/27 dated 14 May 2018. Clinically diagnosed psoriasis patients who visited the dermatology Outpatient Clinic were screened, and 120 patients aged 14-75 years with nail psoriasis were examined clinically and with dermoscope (DermLite DL4, ×10; polarized and non-polarized modes). Onychomycosis was ruled out after performing $\mathrm{KOH}$ mount on nails and fungal cultures from all the suspected cases.
Patients with coexisting onychomycosis, erythrodermic psoriasis, patients in remission following systemic treatment for psoriasis, pregnant women, patients not consenting to the study, and patients with systemic disorders that may have influenced nail changes were excluded from the study. The clinical-demographic profile of the participants was documented. Clinical images of the hands and feet and radiographs were taken, and the Classification Criteria for Psoriatic Arthritis (CASPAR) scores were calculated.

Disease severity was assessed using Psoriasis Area Severity Index (PASI) as a clinical assessment tool for each patient. All nails were examined clinically followed by a dermoscopic examination. Dermoscopic images were captured with DermLite DL4, $\times 10$, polarized and non-polarized modes. The Nail Psoriasis Severity Index (NAPSI) and modified NAPSI (mNAPSI) scores were calculated for both fingernails and toenails. With dermoscopic findings we recalculated NAPSI and labeled it dermoscopic NAPSI (dNAPSI) and dermoscopic modified NAPSI (dmNAPSI).

\section{Statistical Analysis}

All characteristics were summarized. For continuous variables, the summary statistics of mean \pm standard deviation (SD) were used. For categorical data, the number and percentage were used in the data summaries and diagrammatic presentation. If the Pvalue/ Zvalue was $<0.05$, then the results were statistically significant; otherwise, they were considered as not statistically significant. A receiver operating characteristic (ROC) curve was plotted for NAPSI, d NAPSI, dmNAPSI, and mNAPSI to compare their predictive ability for clinical joint involvement. The odds ratio of NAPSI and dmNAPSI to their correlation with CASPAR was also analysed. Data were analyzed using SPSS software v.23.0.

\section{Results}

A total of 120 patients with psoriatic nail involvement were included in the study. The mean age of the patients was 47.3 \pm 13.1 years (range 14-74 years). Fifty-five percent of patients had the disease for more than 5 years, and the duration of treatment ranged from 0.2 to 11 years $(4.9 \pm 2.6$ years $)$. The mean body mass index (BMI) of the study population was $26.3 \pm 3.2 \mathrm{~kg} / \mathrm{m}^{2}$. Hypertension was the commonest comorbidity (Table 1 ).

Chronic plaque psoriasis was the commonest clinical presentation $(79.2 \%)$ and $72.5 \%$ of the patients had a PASI score $<10 ; 51.7 \%$ of study subjects had a NAPSI score bewteen 6 and 10 . Arthritis was noted in $11.7 \%$ of cases ( $n=14)$, $90 \%(\mathrm{n}=108)$ had a CASPAR score of 3 or more. The mean numbers of fingernails and toenails affected were $3.5 \pm 1.2$ and $3.6 \pm 1.5$ with a mean NAPSI score of $10.1 \pm 6.1$. A larger number of nail changes were detected with dermoscopy. Nail 
Table 1. Socio-Demographic Details of Patients $(\mathrm{n}=120)$

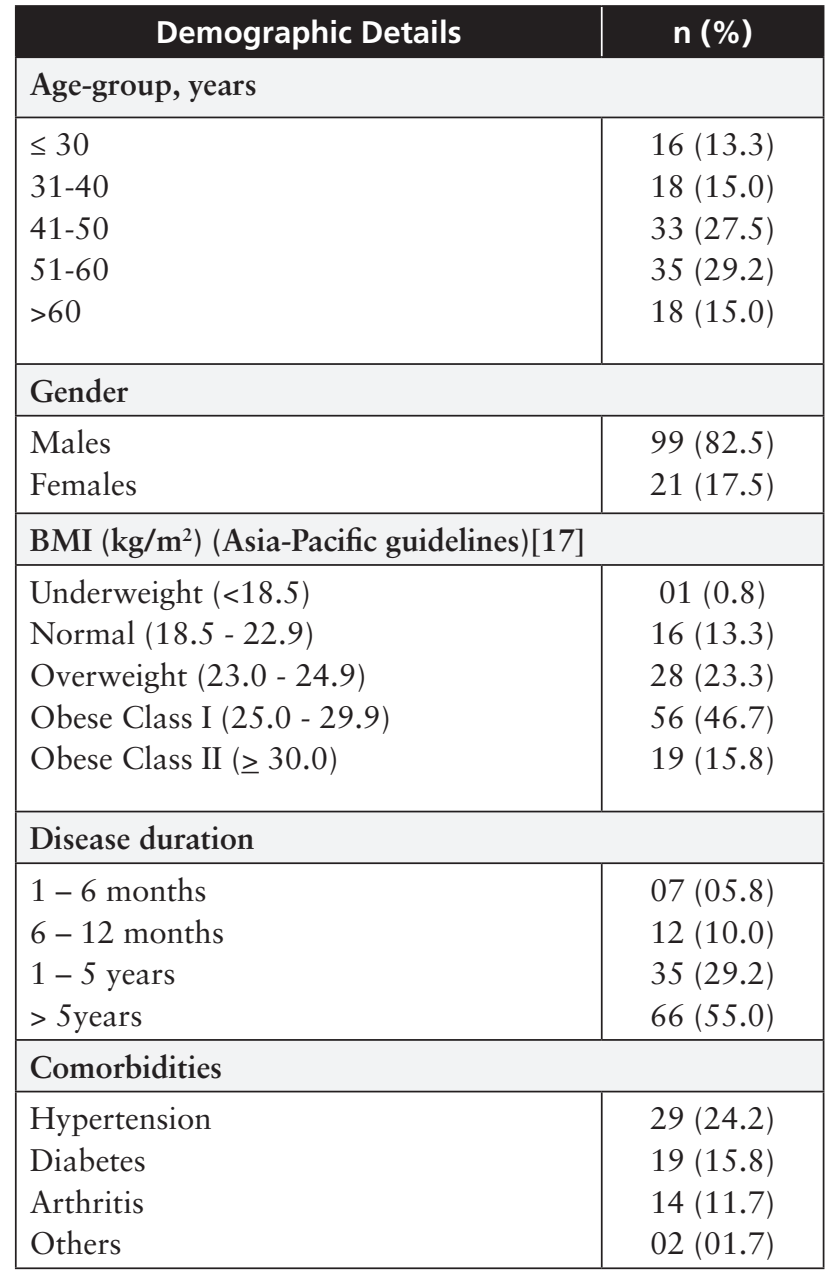

$\mathrm{BMI}=$ body mass index.

matrix signs were noted in $95.8 \%$ of cases and nail bed signs were noted in $85.0 \%$ of cases. Clinically, nail plate thickening $(56.7 \%)$ and subungual hyperkeratosis $(50.8 \%)$ were the most common presentations and, on dermoscopic examination, pitting $(72.5 \%)$ and subungual hyperkeratosis $(68.3 \%)$ the most frequent ones (Figure 1) (Table 2).

The mean (range) of PASI, NAPSI, mNAPSI, dNAPSI and dmNAPSI scores were 7.5 (1.8-36.0), 8.5 (3-39), 7.0 (0-34), $11.0(3-45)$ and $11.0(0-44)$, respectively. NAPSI, mNAPSI and dNAPSI scores increased significantly with the rise in PASI scores $(\mathrm{r}=0.56, \mathrm{P}<0.001),(\mathrm{r}=0.57, \mathrm{P}<0.001)$ and $(\mathrm{r}$ $=0.54, \mathrm{P}<0.001)$, respectively (Figures 2 and 3 ).

The scores of dNAPSI also increased significantly with the increase of mNAPSI and dmNAPSI scores $(\mathrm{r}=0.84$ with $\mathrm{P}<$ 0.001 and $\mathrm{r}=0.87$ with $\mathrm{P}<0.001$, respectively) (Figure 4).

Keeping the variables like age, gender, BMI, NAPSI scores, presence of comorbidities, duration of onset of disease, and duration of treatment constant in for analysis the increase in dNAPSI scores by 1 unit is likely to detect PASI scores $<10$ by 1.08 times and PASI scores between 10 and 20 by 1.01 times compared to PASI scores $>20$. The increase in NAPSI scores by 1 unit is less likely to detect PASI scores $<10$ and between 10 and 20 by 0.69 times compared to PASI scores $>20$. Similarly, the increase in dmNAPSI scores by 1 unit is less likely to detect PASI scores $<10$ by 0.59 times and PASI scores between 10 and 20 by 0.69 times compared to PASI scores $>20$.

The adjusted odds values showed that dNAPSI scores were more likely to detect psoriasis at an early stage compared to NAPSI and dmNAPSI. Although the scores were not significant predictors in detecting psoriasis at an early stage $(\mathrm{P}$ $>0.05$ ) (Table 3), dNAPSI was likely to detect a rise in PASI in moderate-to-severe psoriasis better than NAPSI. Hence, follow-up of cases with this index can alert an impending worsening of the condition.

The receiver operating characteristic (ROC) curve plotted for NAPSI, d NAPSI, dmNAPSI, and mNAPSI to compare their predictive ability for clinical joint involvement revealed that mNAPSI and dmNAPSI were significantly better predictors of joint involvement compared to other nail psoriasis severity indices (NAPSI, dNAPSI) $(\mathrm{P}<0.05)$ (Figure 5).

Though none of the severity measure scores (NAPSI, dNAPSI, mNAPSI and dmNAPSI) were statistically significant $(\mathrm{P}>0.05)$ for joint involvement, dmNAPSI scores showed higher odds ratio values, indicating that unitary increase in dmNAPSI scores increased the odds of being in the CASPAR scores of 2, 3 and 4 by 2.10 times, 2.19 times, and 2.13 times compared to a CASPAR score of 5. Similarly, NAPSI scores showed higher odds ratio values, indicating that unit increase in NAPSI scores increased the odds of being in the CASPAR scores of 2,3 and 4 by 1.58 times, 1.85 times and 2.03 times compared to a CASPAR score of 5 . The odds of NAPSI scores increased with increase in the grades of severity of joint involvement based on CASPAR criteria, and odds of dmNAPSI remained almost the same, with no statistical difference between these two $(\mathrm{P}>0.05)$ (Table 4).

The mean ranks of mNAPSI increased significantly with the duration of the disease $(1-6$ months $=47.57 ; 12-60$ months $=60.00 ;>60$ months $=67.34$, with $\mathrm{P}<0.05)$, except at 6-12 months $(31.88, \mathrm{P}>0.05)$. The mean ranks of other scores, ie dNAPSI, dmNAPSI and NAPSI, did not vary significantly in relation to the durations of the disease $(\mathrm{P}>0.05)$ (Table 5).

\section{Conclusions}

Dermoscopy allows for better visualization of the nail bed and nail matrix abnormalities, and detects early or mild, as well as late changes in the disease, as was also seen in the present study [12]. With its routine use in clinical practice, early and late descriptions of skin, nail and hair diseases are being elaborated in literature increasingly. However, their relevance and importance to standard clinical findings need 


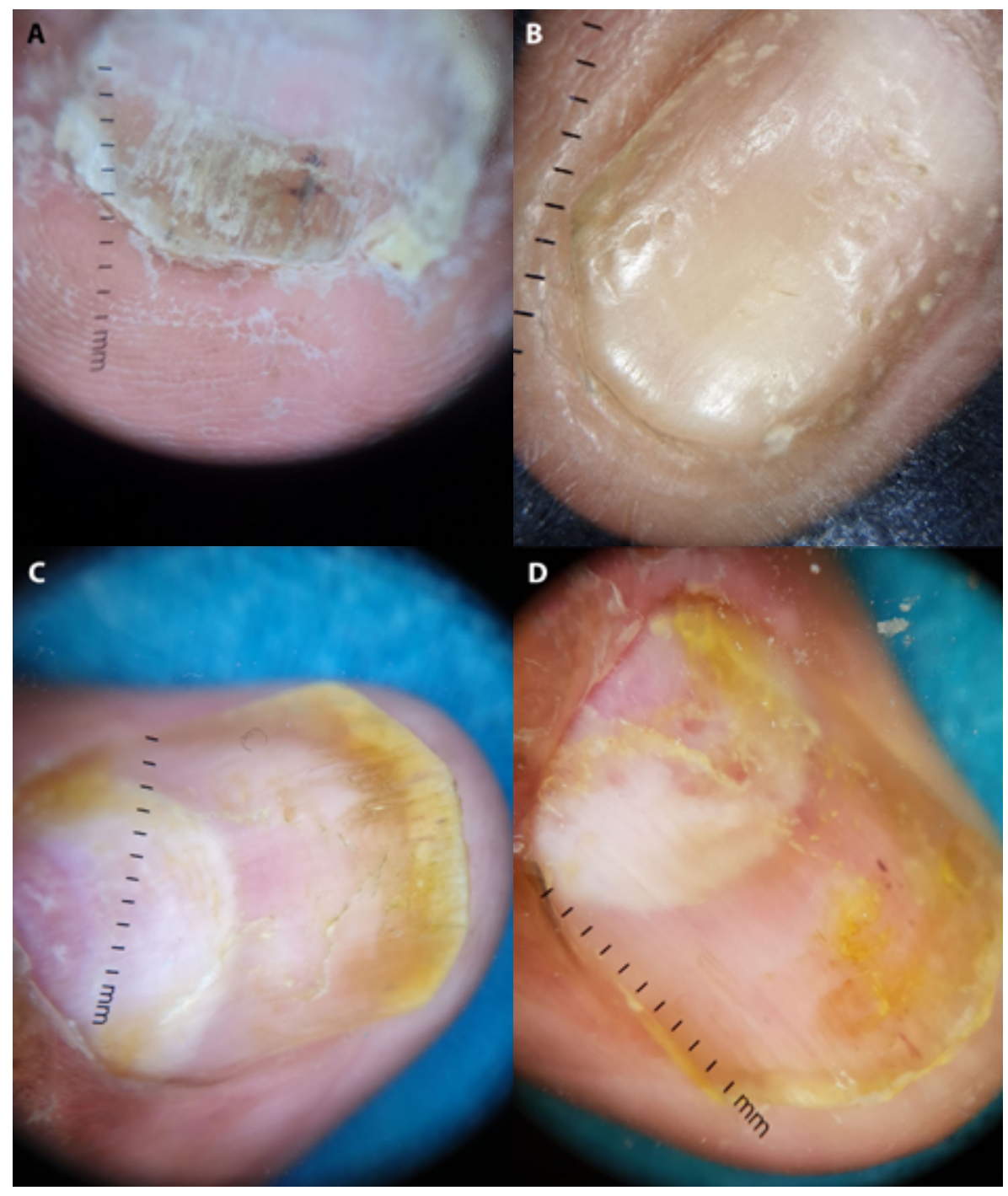

Figure 1. Dermoscopic image. (A) subungual hyperkeratosis. (B) pitting. (C) distal onycholysis. (D) splinter hemorrhages (DermLite DL4, $\times 10$, polarized).

Table 2. Frequency Distribution of Clinical and Dermoscopic Nail Bed and Nail Matrix Findings Among Patients

\begin{tabular}{|c|c|c|c|c|}
\hline \multirow[b]{2}{*}{ Findings } & \multicolumn{2}{|c|}{ Clinical Examination } & \multicolumn{2}{|c|}{ Dermoscopic Examination } \\
\hline & Number (n) & Percentage (\%) & Number (n) & Percentage (\%) \\
\hline \multicolumn{5}{|l|}{ Nail Bed Signs } \\
\hline Splinter hemorrhages & 06 & 05.0 & 31 & 25.8 \\
\hline Subungual hyperkeratosis & 61 & 50.8 & 82 & 68.3 \\
\hline Distal onycholysis & 54 & 45.0 & 62 & 51.7 \\
\hline Oil drop sign & 37 & 30.8 & 47 & 39.2 \\
\hline Dilated hyponychial capillaries & 18 & 15.0 & 18 & 15.0 \\
\hline \multicolumn{5}{|l|}{ Nail Matrix Signs } \\
\hline Nail plate thickening & 68 & 56.7 & 71 & 59.2 \\
\hline Pitting & 60 & 50.0 & 87 & 72.5 \\
\hline Leukonychia & 13 & 10.8 & 26 & 21.7 \\
\hline Transverse grooves & 14 & 11.7 & 24 & 20.0 \\
\hline Trachyonychia & 01 & 0.8 & 14 & 11.7 \\
\hline Red spots on lunula & 04 & 03.3 & 05 & 04.2 \\
\hline Crumbling & 23 & 19.2 & 23 & 19.2 \\
\hline
\end{tabular}



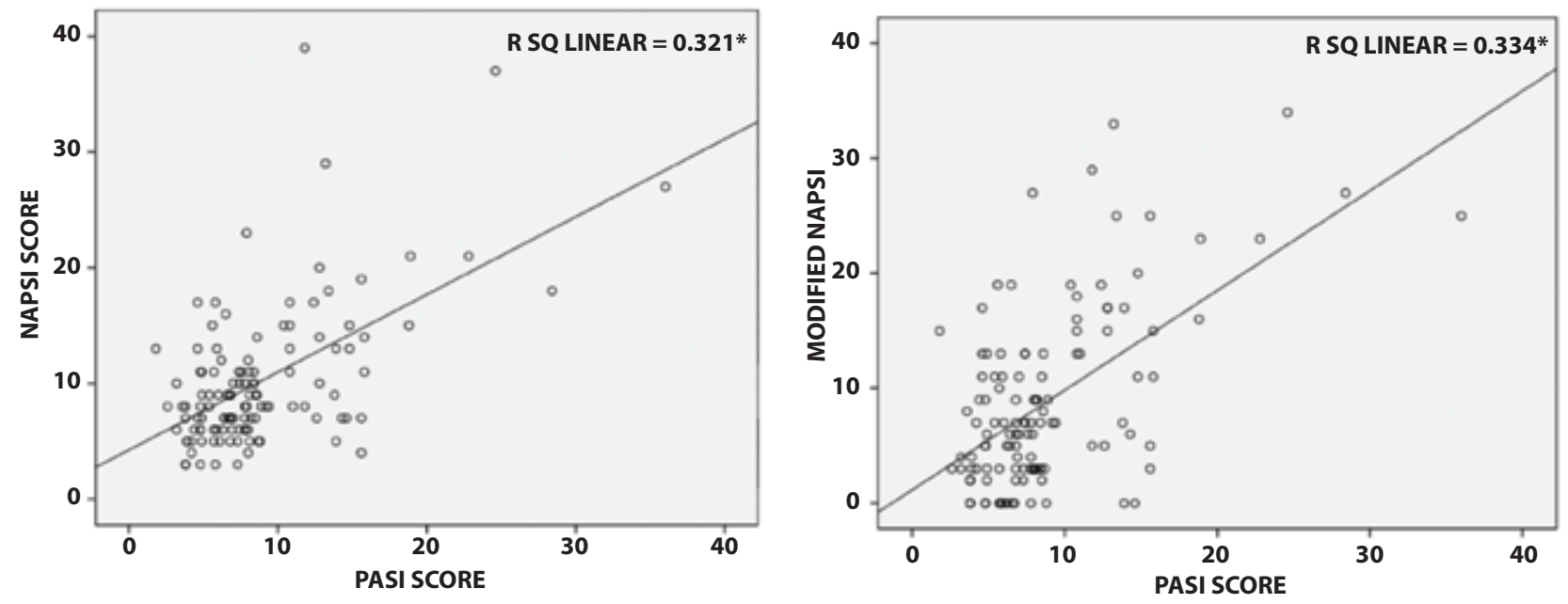

Figure 2. (A) Correlation of PASI and NAPSI scores. (B) Correlation of PASI and mNAPSI scores. mNAPSI = modified Nail Psoriasis Severity Index; PASI = Psoriasis Area Severity Index.

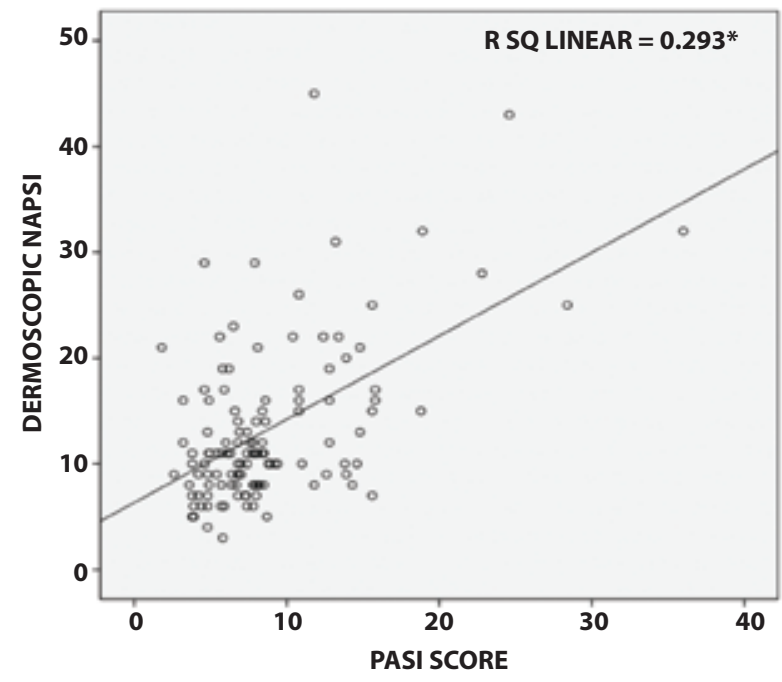

Figure 3. Correlation of PASI and dNAPSI (dermoscopically assessed NAPSI) scores. dNAPSI = dermoscopic Nail Psoriasis Severity Index; PASI = Psoriasis Area Severity Index.

to be validated. In this study we compared nail changes observed in both dermoscopic and clinical examinations and determined their association using NAPSI score and their correlation between the indicators of disease severity, ie PASI and NAPSI scores.

Chronic plaque psoriasis is known to be the commonest pattern of psoriasis, as evidenced in our study. The mean age of our cohort $(47.3 \pm 13.1$ years $)$ with psoriasis was similar to those reported literature [13]. In our study, we had 55\% males and a duration of disease of 4.9 years, which is higher than other studies reporting nail findings $[14,15]$. Elobeid et al found a mean BMI of $25.3 \mathrm{~kg} / \mathrm{m}^{2}$, similar to our findings if not for a marginally higher BMI $\left(26.3 \mathrm{~kg} / \mathrm{m}^{2}\right)$ which may have been due to different study populations and study settings [16][17].

In psoriasis, nail lesions usually manifest 10 years later than skin lesions, and nail involvement is present in $20 \%-50 \%$ of psoriatic patients [18-21]. According to Polat and Kapicioglu, the most common clinical and dermoscopic findings were pitting and leukonychia [12], and Wanniang et al noted salmon patch (oil drop sign) and splinter hemorrhages significantly better with the dermoscope [22]. In addition to pitting, Yorulmaz and Artuz found salmon patch (oil drop sign) to be associated with higher NAPSI scores [13]. However, in our study, pitting, subungual hyperkeratosis, nail plate thickening, and distal onycholysis were present in the majority of patients, and all nail changes were noted significantly better on dermoscopy. The difference in our observations from the reported literature may be due to different disease duration and severity with an average NAPSI score of 8 in our study versus 23, indicating higher disease severity among their patients [22]. Dermoscopic nail findings of subungual hyperkeratosis and oil drop signs were significantly associated with a higher median NAPSI score $>8$ in our study. The scores of NAPSI, mNAPSI and dNAPSI increased significantly with the rise in PASI scores, which partially corroborates the findings of studies by Hallaji et al and Prevezas et al [23,24].

The dNAPSI helped detect early psoriasis but did not perform well in detecting changes in severity in early psoriasis. However, dNAPSI was better than NAPSI at detecting worsening PASI in moderate-to-severe psoriasis.

Cassell et al formulated mNAPSI as a gold standard with good correlation with other disease severity measures [25]. The scores of dmNAPSI along with mNAPSI were found to be significantly better predictors of joint involvement compared to other nail psoriasis severity indices.

Both mNAPSI and dmNAPSI increased with severe joint involvement, based on the CASPAR criteria, with no statistically significant difference between these two scores. Hence, $\mathrm{dmNAPSI}$ is consistent as mNAPSI in correlation with joint severity. 

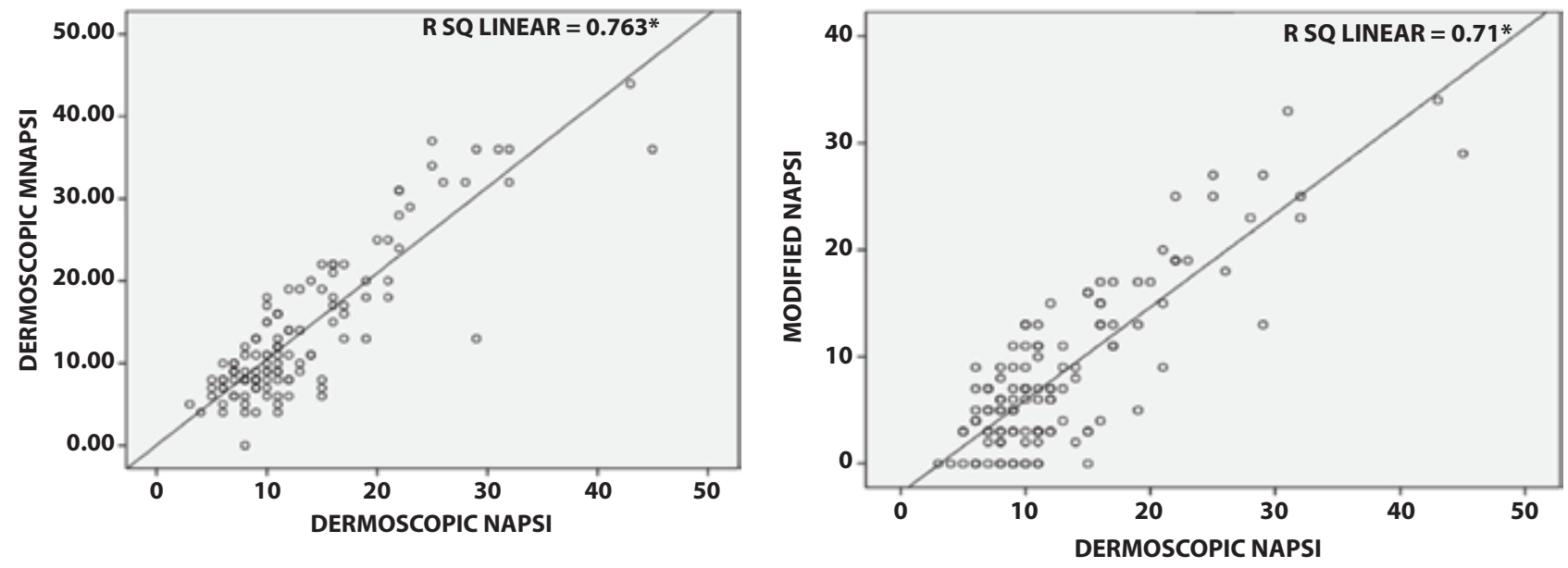

Figure 4. (A) Correlation between dmNAPSI and dNAPSI scores. (B) Correlation between mNAPSI and dNAPSI scores. dNAPSI = dermoscopic Nail Psoriasis Severity Index; dmNAPSI = dermoscopic modified Nail Psoriasis Severity Index; mNAPSI = modified Nail Psoriasis Severity Index.

Table 3. Predictors of Severity of Nail Psoriasis Based on PASI Scores

\begin{tabular}{|c|c|c|c|c|c|}
\hline $\begin{array}{c}\text { PASI Severity } \\
\text { Scores }\end{array}$ & $\begin{array}{c}\text { Measures of } \\
\text { Nail Psoriasis } \\
\text { Severity Index }\end{array}$ & $\begin{array}{c}\text { Unadjusted } \\
\text { Odds Ratio (OR) }\end{array}$ & $\begin{array}{c}\text { Adjusted Odds } \\
\text { Ratio (OR) }\end{array}$ & $\begin{array}{c}\text { 95\% Confidence } \\
\text { Interval (CI) }\end{array}$ & P-value \\
\hline \multirow{3}{*}{$<10$} & dNAPSI & 0.08 & 1.08 & $0.31-3.79$ & 0.90 \\
\cline { 2 - 6 } & NAPSI & -0.36 & 0.69 & $0.25-1.99$ & 0.50 \\
\cline { 2 - 6 } & dmNAPSI $^{\ddagger}$ & -0.52 & 0.59 & $0.34-1.06$ & 0.08 \\
\hline \multirow{3}{*}{$10-20$} & dNAPSI & 0.02 & 1.01 & $0.29-3.52$ & 0.98 \\
\cline { 2 - 6 } & NAPSI & -0.36 & 0.69 & $0.25-1.95$ & 0.49 \\
\cline { 2 - 6 } & dmNAPSI $^{¥}$ & -0.38 & 0.69 & $0.39-1.20$ & 0.19 \\
\hline
\end{tabular}

Reference Category: PASI score more than 20;

\-dermoscopic NAPSI; $¥$ - dermoscopic modified NAPSI

dNAPSI = dermoscopic NAPSI; dmNAPSI = dermoscopic modified NAPSI; NAPSI = Nail Psoriasis Severity Index; PASI = Psoriasis Area and Severity Index

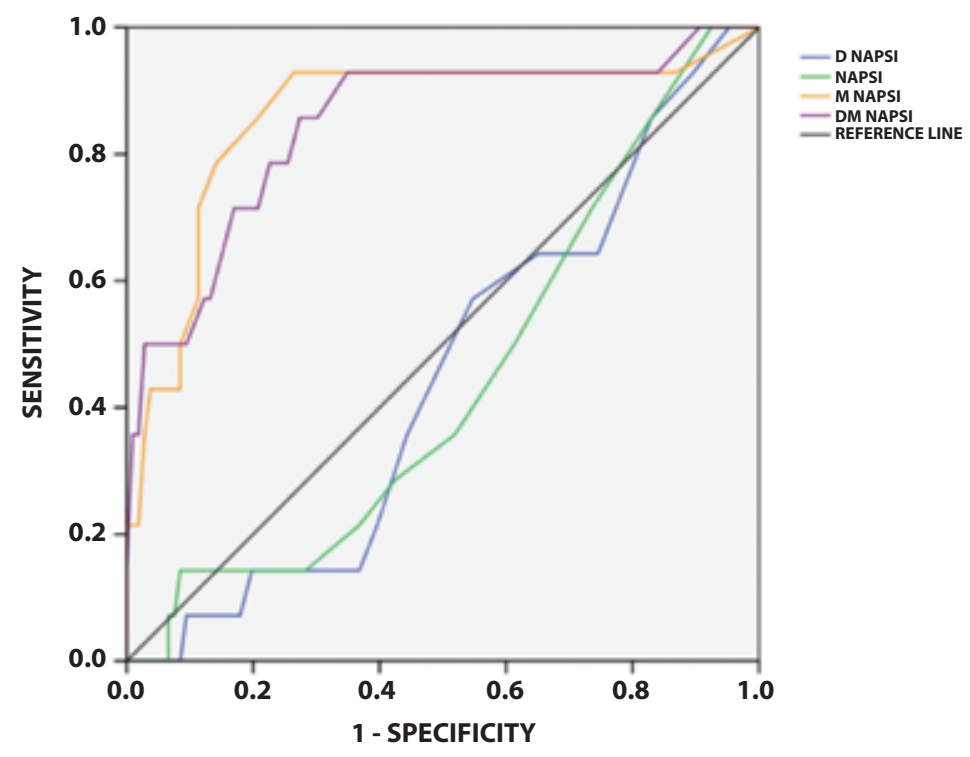

Figure 5. Predictive ability of NAPSI, mNAPSI, dmNAPSI, and dNAPSI in detecting joint involvement. dNAPSI = dermoscopic Nail Psoriasis Severity Index; dmNAPSI $=$ dermoscopic modified Nail Psoriasis Severity Index; mNAPSI $=$ modified Nail Psoriasis Severity Index; NAPSI = Nail Psoriasis Severity Index. 
Table 4. Comparison of Measures of Nail Psoriasis Severity Indices as Predictors of Psoriatic Arthritis Based on CASPAR Criteria

\begin{tabular}{|c|c|c|c|c|c|}
\hline CASPAR Criteria & $\begin{array}{l}\text { Measures of Nail } \\
\text { Psoriasis Severity } \\
\text { Index }\end{array}$ & $\begin{array}{c}\text { Unadjusted } \\
\text { Odds Ratio (OR) }\end{array}$ & $\begin{array}{c}\text { Adjusted } \\
\text { Odds Ratio } \\
\text { (OR) }\end{array}$ & $\begin{array}{c}95 \% \\
\text { Confidence } \\
\text { Interval (Cl) }\end{array}$ & P-value \\
\hline \multirow[t]{4}{*}{2} & dNAPSI $^{\S}$ & -0.02 & 0.99 & $0.48-2.02$ & 0.97 \\
\hline & mNAPSI & -0.79 & 0.46 & $0.15-1.35$ & 0.16 \\
\hline & NAPSI & 0.46 & 1.58 & $0.54-4.62$ & 0.40 \\
\hline & dmNAPSI $^{¥}$ & 0.74 & 2.10 & $0.69-6.45$ & 0.19 \\
\hline \multirow[t]{4}{*}{3} & dNAPSI $^{\S}$ & -0.25 & 0.78 & $0.39-1.55$ & 0.47 \\
\hline & mNAPSI & -0.87 & 0.42 & $0.15-1.22$ & 0.11 \\
\hline & NAPSI & 0.62 & 1.85 & $0.85-5.28$ & 0.25 \\
\hline & $\mathrm{dmNAPSI}^{¥}$ & 0.79 & 2.19 & $0.73-6.61$ & 0.16 \\
\hline \multirow[t]{4}{*}{4} & dNAPSI $^{\S}$ & -0.31 & 0.74 & $0.35-1.54$ & 0.42 \\
\hline & mNAPSI & -0.75 & 0.48 & $0.16-1.40$ & 0.18 \\
\hline & NAPSI & 0.71 & 2.03 & $0.68-6.02$ & 0.20 \\
\hline & dmNAPSI ${ }^{¥}$ & 0.76 & 2.13 & $0.69-6.52$ & 0.19 \\
\hline
\end{tabular}

Reference Category: CASPAR criteria of 5;

S-dermoscopic NAPSI; $¥$ - dermoscopic modified NAPSI

CASPAR = Classification Criteria for Psoriatic Arthritis; dNAPSI = dermoscopic NAPSI; dmNAPSI = dermoscopic modified NAPSI; NAPSI = Nail Psoriasis Severity Index; PASI = Psoriasis Area and Severity Index.

Table 5. Comparison of Mean Ranks of Nail Psoriasis Severity Index Among Different Durations of Onset of Disease in Months

\begin{tabular}{|c|c|c|c|c|c|}
\hline \multirow{2}{*}{$\begin{array}{l}\text { Measures of nail } \\
\text { psoriasis severity } \\
\text { index }\end{array}$} & \multicolumn{4}{|c|}{ Duration of Onset in Months } & \multirow[b]{2}{*}{$\begin{array}{l}Z \text { value } \\
\text { (P value) }\end{array}$} \\
\hline & $1-6(n=7)$ & $6-12(n=12)$ & $12-60(n=35)$ & $>60(n=66)$ & \\
\hline $\begin{array}{c}\text { Mean ranks of } \\
\text { dNAPSI }^{\S}\end{array}$ & 53.07 & 69.38 & 69.74 & 54.77 & $\begin{array}{c}5.39 \\
(0.15)\end{array}$ \\
\hline $\begin{array}{c}\text { Mean ranks of } \\
\text { mNAPSI }^{¥}\end{array}$ & 47.57 & 31.88 & 60.00 & 67.34 & $\begin{array}{c}11.74 \\
(0.008)^{*}\end{array}$ \\
\hline $\begin{array}{l}\text { Mean ranks of } \\
\text { NAPSI }\end{array}$ & 59.86 & 63.13 & 68.60 & 55.80 & $\begin{array}{c}3.19 \\
(0.36)\end{array}$ \\
\hline $\begin{array}{c}\text { Mean ranks of } \\
\text { dmNAPSI }\end{array}$ & 43.79 & 45.12 & 58.99 & 65.87 & $\begin{array}{c}5.63 \\
(0.13)\end{array}$ \\
\hline
\end{tabular}

¥-modified NAPSI; $\mathbb{S}$-dermoscopic NAPSI; *statistically significant difference at $\mathrm{P}<0.05$

dNAPSI = dermoscopic NAPSI; dmNAPSI = dermoscopic modified NAPSI; NAPSI = Nail Psoriasis Severity Index.

The mean ranks of mNAPSI increased significantly with duration of onset of disease, except at 6-12 months. The mean ranks of other scores, ie dNAPSI, dmNAPSI and NAPSI, did not vary significantly across the durations of onset of disease.

Our aim in this study was to utilize the dermoscope to detect nail changes in psoriasis, and it revealed that nail changes are better visualized and detected earlier. Nail scoring for psoriasis utilizing dNAPSI helps in the early diagnosis and assessment and detection of worsening moderate-to-severe psoriasis (PASI $>10$ ) as compared to NAPSI. The use of dermoscopy for detecting joint severity as per CASPAR criteria was consistent with naked-eye assessment of nail findings. However, as none of these indices proved to be statistically significant by themselves, their true significance may be revealed with larger studies using dNAPSI and dmNAPSI. We do recommend the use of a dermoscope as a routine tool in assessing nail psoriasis. 


\section{References}

1. de Jong EM, Seegers BA, Gulinck MK, Boezeman JB, van de Kerkhof PC. Psoriasis of the nails associated with disability in a large number of patients: results of a recent interview with 1,728 patients. Dermatology. 1996;193(4):300-303. DOI: 10.1159/000246274. PMID: 8993953.

2. Reich A, Szepietowski JC. Health-Related Quality of Life in Patients with Nail Disorders. Am J Clin Dermatol. 2011;12(5):313320. DOI: 10.2165/11592120-000000000-00000. PMID: 21834596.

3. Dogra A, Arora AK. Nail Psoriasis: The Journey So Far. Indian J Dermatol. 2014;59(4):319-333. DOI: 10.4103/00195154.135470. PMID: 25071247; PMCID: PMC4103264.

4. Schons KRR, Beber AAC, Beck M de O, Monticielo OA. Nail involvement in adult patients with plaque-type psoriasis: prevalence and clinical features. An Bras Dermatol. 2015;90(3):314-319. DOI: 10.1590/abd1806-4841.20153736. PMID: 26131859; PMCID: PMC4516108.

5. Reich K. Approach to managing patients with nail psoriasis. J Eur Acad Dermatol Venereol. 2009;23 Suppl 1:15-21. DOI: 10.1111/j.1468-3083.2009.03364.x. PMID: 19686381.

6. Salomon J, Szepietowski JC, Proniewicz A. Psoriatic nails: a prospective clinical study. J Cutan Med Surg. 2003;7(4):317-321. DOI: 10.1007/s10227-002-0143-0. PMID: 12879333.

7. Edwards F, de Berker D. Nail psoriasis: clinical presentation and best practice recommendations. Drugs. 2009;69(17):2351-2361. DOI: 10.2165/11318180-000000000-00000. PMID: 19911853.

8. Jiaravuthisan MM, Sasseville D, Vender RB, Murphy F, Muhn CY. Psoriasis of the nail: anatomy, pathology, clinical presentation, and a review of the literature on therapy. J Am Acad Dermatol. 2007;57(1):1-27. DOI: 10.1016/j.jaad.2005.07.073. PMID: 17572277.

9. Gupta AK, Cooper EA. Psoriatic nail disease: quality of life and treatment. J Cutan Med Surg. 2009;13 Suppl 2:S102-S106. DOI: 10.2310/7750.2009.00027. PMID: 1979982.

10. Micali G, Lacarrubba F, Massimino D, Schwartz RA. Dermatoscopy: Alternative uses in daily clinical practice. J Am Acad Dermatol. 2011;64(6):1135-1146. DOI: 10.1016/j.jaad.2010.03.010. PMID: 21292346.

11. Farias DC de, Tosti A, Chiacchio ND, Hirata SH. [Dermoscopy in nail psoriasis]. An Bras Dermatol. 2010;85(1):101-103. DOI: 10.1590/s0365-05962010000100017. PMID: 20464097.

12. Polat A, Kapıcıoğlu Y. Dermoscopic findings of psoriatic nail and their relationship with disease severity. TURKDERM. 2017;51:119-23. DOI: 10.4274/turkderm.54289.

13. Yorulmaz A, Artuz F. A study of dermoscopic features of nail psoriasis. Postepy Dermatol Alergol. 2017;34(1):28-35. DOI: 10.5114/ada.2017.65618. PMID: 28286468; PMCID: PMC5340855.
14. Yadav TA, Khopkar US. Dermoscopy to Detect Signs of Subclinical Nail Involvement in Chronic Plaque Psoriasis: A Study of 68 Patients. Indian J Dermatol. 2015;60(3):272-275. DOI: 10.4103/00195154.156377. PMID: 26120154; PMCID: PMC4458939.

15. Prabhakar V, Joy B, Thyvalappil A, Sridharan R, Sreenivasan A, Mathew P. Prevalence, clinical profile, and severity of nail involvement in psoriasis - A hospital-based cross-sectional study from a tertiary care center in North Kerala. J Skin Sex Transm Dis 2019;1(2):72-6.

16. Elobeid HE, Alfarouk KO, Ahmed N. Aljarbou AN, et al. Correlation between the Body Mass Index and Psoriasis in Dermatology and Venereology Teaching Hospital in Khartoum. AJDV. 2017;6:30-39. doi:10.5923/j.ajdv.20170602.03

17. Misra A. Ethnic-Specific Criteria for Classification of Body Mass Index: A Perspective for Asian Indians and American Diabetes Association Position Statement. Diabetes Technol Ther. 2015;17(9):667-671. doi:10.1089/dia.2015.0007

18. The Etiology, Pathophysiology,Differential Diagnosis, Clinical Findings, and Treatment of Nail Psoriasis I IntechOpen [Internet]. [cited 2020 Jun 17]. Available from: https://www.intechopen.com/ chapters/66296

19. Farber EM, Nall ML. The natural history of psoriasis in 5,600 patients. Dermatologica. 1974;148(1):1-18. DOI: 10.1159/000251595. PMID: 4831963.

20. Armesto S, Esteve A, Coto-Segura P, et al. [Nail psoriasis in individuals with psoriasis vulgaris: a study of 661 patients]. Actas Dermosifiliogr. 2011;102(5):365-72. DOI: 10.1016/j. ad.2011.02.007. PMID: 21514549.

21. Baran R. The burden of nail psoriasis: an introduction. Dermatology. 2010;221 Suppl 1:1-5. DOI: 10.1159/000316169. PMID: 20733309.

22. Wanniang N, Navya A, Pai V, Ghodge R. Comparative study of clinical and dermoscopic features in nail psoriasis. Indian Dermatol Online J. 2020;11(1):35-40. DOI: 10.4103/idoj.IDOJ_51_19. PMID: 32055506; PMCID: PMC7001394.

23. Hallaji Z, Babaeijandaghi F, Akbarzadeh M, et al. A significant association exists between the severity of nail and skin involvement in psoriasis. J Am Acad Dermatol. 2012;66(1):e12-13. DOI: 10.1016/j.jaad.2010.10.021. PMID: 22177647.

24. Prevezas C, Katoulis AC, Papadavid E, Panagakis P, Rigopoulos D. Short-Term Correlation of the Psoriasis Area Severity Index, the Nail Psoriasis Area Severity Index, and the Dermatology Life Quality Index , before and after Treatment, in Patients with Skin and Nail Psoriasis. Skin Appendage Disord. 2019;5(6):344349. DOI: 10.1159/000499348.. PMID: 31799260; PMCID: PMC6883452.

25. Cassell S, Bieber J, Rich P, et al. The modified Nail Psoriasis Severity Index: Validation of an instrument to assess psoriatic nail involvement in patients with psoriatic arthritis. J Rheumatol. 2007;34(1):123-129. PMID: 17216680. 